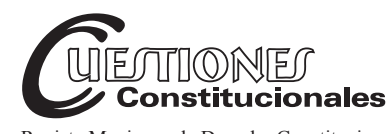

Revista Mexicana de Derecho Constitucional Núm. 43, julio-diciembre 2020

\title{
La frontera móvil entre constitucionalidad y legalidad en la procedencia del amparo directo en revisión
}

\author{
The moving boundary between constitutionality and legality \\ within the "amparo directo en revisión"
}

\section{Roberto LARA CHAGOYÁN*}

A José Ramón Cossio Díaz, con gratitud y admiración.

RESUMEN: El presente artículo se ocupa de plantear, denunciar y analizar un problema relacionado con la enorme discrecionalidad que se genera a la hora en que la Corte Suprema de nuestro país decide la procedencia de un recurso de revisión en amparo directo. Demostraré que el enunciado "La Suprema Corte, en su papel de tribunal constitucional, sólo debe ocuparse de cuestiones propiamente constitucionales" es manifiestamente falso, porque la propia legislación y la jurisprudencia aplicables permiten que la procedencia de dicho recurso dependa más de la discrecionalidad de los ministros - tolerada por el propio sistema- que de reglas precisas y objetivas.

Asimismo, expondré las razones que a mi juicio han provocado esta situación y las consecuencias nocivas que genera, especialmente con relación al principio de igualdad.
ABSTRACT: This paper focuses on presenting, exposing and analysing a problem concerning a great deal of discretion generated when our country's Supreme Court decides on the admissibility of a "amparo directo en revision". I will demonstrate that the following sentence: "The Supreme Court, as a Constitutional Court, should only concern itself with actual constitutional issues", is manifestly untrue, because the applicable law and the judicial precedents enable the admissibility of such motion of review at the discretion of the Ministers - tolerated by the system itself - more so than by specific and objective laws.

Moreover, I will set out the reasons that, in my opinion, have caused this situation, as well as the negative impacts it generates, especially related to the principle of equality.

* Profesor-investigador en el Departamento de Derecho del Tecnológico de Monterrey, campus Santa Fe, en la Ciudad de México. México. ORCID: 0000-0003-1692-8826. Correo electrónico: roberto.larac@gmail.com.

Agradezco los comentarios críticos y agudos de Dulce Alejandra Camacho Ortiz y Camilo Emiliano Saavedra Herrera, sin los cuales las sucesivas versiones de este trabajo no habrían visto evolución alguna. 
Palabras clave: constitucionalidad, legalidad, amparo directo, procedencia, jurisprudencia, constitucionalismo, formalismo, activismo judicial, regla de justicia formal.
Keywords: constitutionality, legality, "amparo directo", admissibility, jurisprudence, constitutionalism, formalism, judicial activism, formal justice rule.

SUMARIO: I. Introducción. II. Planteamiento del problema. III. El origen histórico de la confusión terminológica y una propuesta de clarificación. IV. Una frontera móvil en la jurisprudencia mexicana. V. Rastreando las causas que explican el fenómeno. VI. Conclusiones. VII. Bibliohemerografía.

\section{INTRODUCCIÓN}

En los tiempos que corren, en los que los sistemas jurídicos están "absolutamente impregnados de constitucionalidad", ${ }^{1}$ no sólo es deseable, sino también exigible, que los conflictos que se resuelven mediante la aplicación de normas tengan como brújula los valores constitucionales en sentido amplio, es decir, incluyendo los que se recogen en los bloques de constitucionalidad o parámetros de control de la regularidad constitucional. El Poder Constituyente Permanente parece haberse tomado en serio este propósito al haber reformado el 10 de junio de 2011 el artículo 1o. de la Constitución mexicana, mediante una serie de cláusulas que reflejan un compromiso fuerte con la cultura de los derechos humanos, para lo cual se establecieron una serie de obligaciones consistentes en promover, respetar, proteger y garantizar los derechos humanos.

Sin embargo, bien entendido, ese noble fin no puede significar que los operadores jurídicos desconozcan o dejen de atender, sin más, lo que ordenan las leyes ordinarias, a menos que éstas contradigan aquellos valores. En otras palabras, el advenimiento del llamado paradigma constitucionalista no puede ser entendido como un permiso fuerte para dejar de seguir los procedimientos o cumplir los deberes que imponen las normas secundarias, ya que, por el contrario, atenderlas — cuando en sí mismas no constituyen desobediencia constitucional - contribuye al cumplimiento de los fines constitucionalmente protegidos.

1 Favoreau, Louis, Legalidad y constitucionalidad. La constitucionlización del derecho, traducción de Magdalena Correa Heano, Bogotá, Universidad Externado de Colombia, Instituto de Estudios Constitucionales Carlos Restrepo Piedrahita, 2000, p. 69. 
El juez, a diferencia del jurista teórico, debe aplicar el derecho vigente cada día para realizar su trabajo, y por ello experimenta con mayor nitidez algunas tensiones que pueden darse entre la "constitucionalización" del sistema y los límites que los textos legales le imponen para actuar.

Uno de estos casos es el que analizaré en este trabajo. Se trata de la procedencia del recurso de revisión en el amparo directo que corresponde conocer en exclusiva a la Suprema Corte de Justicia de la Nación (SCJN), quien decide si un recurso resulta o no procedente, lo cual depende básicamente del tipo de problema de que se trate: si es de legalidad, entonces resultará improcedente, y, por lo tanto, deberá desecharse; en cambio, si es de constitucionalidad, entonces resultará procedente, será admitido y se analizará de fondo. ${ }^{2}$

Como se verá, en este tipo de decisiones los operadores jurídicos deben tomar en cuenta elementos normativos, provenientes de reglas constitutivas (deben analizar si un determinado recurso reúne una serie de características definidas en el sistema jurídico para ser considerado como procedente), pero también aspectos valorativos (ejercicios discrecionales) mediante los cuales debe complementar la decisión sobre la procedencia. Los elementos normativos se refieren a que la sentencia recurrida trate de la posible inconstitucionalidad de una norma general o de la interpretación directa de la Constitución, mientras que los elementos valorativos están relacionados con la importancia y trascendencia de la decisión que resulte.

La mezcla de estos elementos ha generado que en la práctica se haya trazado una frontera móvil entre la legalidad y la constitucionalidad, que condiciona la procedencia. Dicha movilidad genera que no siempre se respete la regla de justicia formal, según la cual debe otorgarse un trato igual a los seres pertenecientes a una misma categoría. ${ }^{3}$ Esta situación es particularmente importante si se toma en cuenta que en nuestro juicio de amparo es más benéfico para el interesado que su asunto sea tratado como un tema de constitucionalidad, que si se lo trata como uno de legalidad.

2 El desechamiento "de plano", es decir, sin resolución, corresponde a la presidencia de la Corte, pero el auto correspondiente puede ser impugnado mediante un recurso de reclamación en el que se determina si el tema es de legalidad o de constitucionalidad (artículo 104 de la Ley de Amparo). Todavía las Salas de la Corte o el tribunal pleno pueden volver a discutir la procedencia y actuar en consecuencia.

3 Perelman, Chaïm y Olbretchs-Tyteca, Lucie, Tratado de la argumentación. La nueva retórica, traducción de Julia Sevilla Muñoz, Madrid, Gredos, 1989, p. 340. 
Así pues, uno de los propósitos que persigo en este trabajo es poner en evidencia la movilidad de la frontera entre legalidad y constitucionalidad en los hechos. El otro propósito es mostrar las razones que están detrás de esas variaciones.

El contexto de descubrimiento de este análisis se remonta a mis años como secretario de estudio y cuenta (letrado) en la SCJN, entre 2004 y 2015, cuando tuve que analizar la procedencia de este tipo de recursos. Durante esos años, la perplejidad que me causó el hecho de que un mismo tipo de caso pudiera caer en el sector de la legalidad o de la constitucionalidad me llevó a reflexionar sobre las razones que podían explicar este juego de significados, cuyas consecuencias no eran menores.

Procederé de la siguiente manera: en primer lugar (II, infra), plantearé los extremos del problema que voy a analizar; en un segundo apartado (III, infra), describiré cómo se generó la confusión entre los términos legalidad y constitucionalidad, mediante una breve reseña del llamado amparo casación o de legalidad; en tercer lugar (IV, infra) describiré cómo, de hecho, la Corte ha venido usando las categorías legalidad y constitucionalidad en un periodo determinado; en seguida ( $\mathrm{V}$, infra), expondré las razones que a mi juicio explican el fenómeno, así como las consecuencias negativas de esta práctica; finalmente, en el apartado de conclusiones (VI, infra), aislaré los hallazgos encontrados, y esbozaré apenas algunas pinceladas orientadas a reflexionar en torno a posibles soluciones para estabilizar la frontera móvil entre legalidad y constitucionalidad.

\section{PLANTEAMIENTO DEL PROBLEMA}

Es un tópico en el derecho mexicano considerar que la materia del recurso de revisión en el amparo directo, a cargo de la SCJN, debe limitarse a la decisión de las "cuestiones propiamente constitucionales". Y lo es, porque más allá de que así lo disponga la propia Constitución (artículo 107, fracción IX), nuestra evolución constitucional ha buscado consolidar a la Corte como un auténtico tribunal constitucional.

La fracción IX del artículo 107, a partir de la adición al texto de la Constitución, del 19 de febrero de 1951, estableció que la regla para determinar en qué casos procedía el recurso de revisión en amparo directo ante la Suprema Corte de Justicia de la Nación se reducía a determinar si la sentencia recurrida decidía sobre la inconstitucionalidad de una ley o establecía la interpretación directa de la Constitución. 
El 11 de junio de 1999 se publicó en el Diario Oficial de la Federación $(D O F)$ una reforma a este precepto, impulsada por el presidente Ernesto Zedillo, mediante la cual se agregó un requisito más: que la decisión "entrañe" un criterio de importancia y trascendencia, a juicio de la Suprema Corte de la Nación, en cumplimiento de sus acuerdos generales. La más reciente reforma a la misma disposición tuvo lugar el 6 de junio de 2011 durante el sexenio de Felipe Calderón; en ella se cambió ligeramente la redacción en el sentido de que lo que se debe determinar - a fin de que el recurso resulte procedente - es si las sentencias recurridas (en plural) deciden sobre la constitucionalidad de una ley (anteriormente decía inconstitucionalidad) o establecen la interpretación directa de un precepto de la Constitución, u omiten decidir sobre tales cuestiones cuando hubieren sido planteadas. Como puede verse, con esta última reforma se aumentaron los supuestos de procedencia, ya que ahora no sólo procede el recurso en contra de sentencias que resuelven que un precepto legal es inconstitucional, sino también en contra de sentencias que declaran que un precepto determinado resulta constitucionalmente válido; asimismo, ahora el recurso procede no sólo contra sentencias que decidan sobre tales cuestiones, sino también contra aquellas que omitan hacerlo.

Con todo, lo más relevante de esta serie de prescripciones es el criterio valorativo de importancia y trascendencia. Esto quiere decir que a partir de la reforma de 1999 la SCJN está constitucionalmente facultada para desechar recursos de revisión en amparo directo que no consideren importantes y trascendentes aun cuando en la sentencia contra la que se dirigen se hubiera decidido sobre la constitucionalidad de una ley o se hubiera llevado a cabo la interpretación directa de algún precepto constitucional.

El texto vigente de la Constitución que regula la procedencia del recurso de revisión en amparo directo es el siguiente (se añade énfasis):

Artículo 107. Las controversias de que habla el artículo 103 de esta Constitución, con excepción de aquellas en materia electoral, se sujetarán a los procedimientos que determine la ley reglamentaria, de acuerdo con las bases siguientes:

IX. En materia de amparo directo procede el recurso de revisión en contra de las sentencias que resuelvan sobre la constitucionalidad de normas generales, establezcan la interpretación directa de un precepto de esta Constitución u omitan decidir sobre tales cuestiones cuando hubieren sido planteadas, siempre que fijen un criterio de importancia y trascendencia, 
según lo disponga la Suprema Corte de Justicia de la Nación, en cumplimiento de los acuerdos generales del Pleno. La materia del recurso se limitará a la decisión de las cuestiones propiamente constitucionales, sin poder comprender otras. ${ }^{4}$

El más reciente acuerdo general que regula la procedencia del amparo directo es el 9/2015. En él, además de repetirse las mismas reglas contenidas en la Constitución y en la Ley de Amparo, se establece que la importancia y trascendencia se deriva de los siguientes supuestos: a) cuando la resolución de que se trate dé lugar a “...un pronunciamiento novedoso o de relevancia para el orden jurídico nacional (énfasis añadido)", y b) cuando en la resolución se desconozca algún criterio de la SCJN. Al intentar definir importancia y trascendencia, el acuerdo referido fracasa, pues sencillamente refiere que lo "importante y trascendente" debe entenderse como lo "novedoso o relevante". El acuerdo, pues, viola la regla de la definición, según la cual el definiens debe ser más claro que el definendum.

Llamaré requisitos conceptuales a los relacionados con la constitucionalidad de normas generales y la interpretación directa de la Constitución, y requisito discrecional al relacionado con la nota de importancia y trascendencia. De este modo, de acuerdo con la normatividad aplicable, para que un recurso de revisión resulte procedente no basta con agotar alguno de los requisitos conceptuales (que son los más intuitivos), sino que además es necesario que se cumpla el discrecional. Lo anterior se traduce en que un determinado caso puede ser conceptualmente constitucional, pero si discrecionalmente no resulta importante o trascendente, entonces puede no resultar procedente. Esto significa, al contrario de la intuición general, que el requisito discrecional (importancia y trascendencia) constituye una condición necesaria y suficiente de la constitucionalidad, mientras que los requisitos conceptuales son meramente contingentes. Sobra decir que la vaguedad de los conceptos importancia y trascendencia permite que los operadores jurídicos seleccionen los casos con un enorme grado de discrecionalidad, lo que provoca la movilidad de la frontera entre lo procedente y lo improcedente, que no siempre se corresponde con el binomio conceptual constitucionalidad-legalidad.

4 Esta norma constitucional fue reproducida textualmente en la Ley de Amparo, concretamente, en el último párrafo del artículo 81, fracción II. 
¿De qué depende entonces la decisión de la procedencia? ¿De la correcta aplicación de una regla? ¿Del resultado de un análisis conceptual según el cual el caso X reúne o no las características del concepto constitucionalidad (connotación) o de si X entra o no en el campo de aplicación de dicho concepto (denotación)? La respuesta es que de ninguna de ellas es determinante. La nota definitoria, se insiste, es más bien la valoración derivada de los conceptos importancia y trascendencia, más vagos aún que los de constitucionalidad o legalidad. Todos estos elementos permiten a los ministros de la SCJN “convertir" un caso que en pureza era de legalidad en constitucionalidad, y viceversa. Importancia y trascendencia son entonces conceptos valorativos, que para su utilización no dependen de la aplicación de una regla, sino de un ejercicio de discrecionalidad, del que a veces se abusa.

\section{EL ORIGEN HISTÓRICO DE LA CONFUSIÓN TERMINOLÓGICA Y UNA PROPUESTA DE CLARIFICACIÓN}

¿Cómo se ha entendido históricamente la constitucionalidad y la legalidad en esta materia? Para responder esta pregunta debemos remontarnos al siglo XIX, en los albores del juicio de amparo, cuando éste no procedía en contra de sentencias emitidas por los tribunales ordinarios, es decir, no existía el llamado amparo judicial o amparo casación (el actual amparo directo). En efecto, el artículo 8o. de la Ley de Amparo de 1869 lo prohibía expresamente. ${ }^{5}$ Pero esa prohibición no impidió que la SCJN, mediante la que algunos consideran una "desafortunada" interpretación del artículo 14 de la Constitución de 1857, abriera la puerta al amparo judicial. Dicha interpretación condicionaría el desarrollo y la evolución de nuestro juicio de amparo. Para algunos, provocó que se "desdibujara la original ideal del juicio de amparo", ${ }^{6}$ y más que eso: supuso la "corrupción del juicio de amparo". 7

5 Serna de la Garaza, José María, "El amparo-casación en el pensamiento de Emilio Rabasa”, en González Martín, Nuria (comp.), Estudios jurídicos en homenaje a Marta Morineau, t. I: Derecho romano. Historia del derecho, México, UNAM, Instituto de Investigaciones Jurídicas, 2006, p. 488.

6 Fix-Zamudio, Héctor, "El amparo mexicano como instrumento protector de los derechos humanos", en Garantías jurisdiccionales para la defensa de los derechos, México, UNAM, 1993, p. 256.

7 Rabasa, Emilio, El artículo 14 y el juicio constitucional, México, Porrúa 1993, p. 313 . 
El enunciado a interpretar, contenido en el artículo 14 de la Constitución de 1857, era el siguiente: "Nadie podrá ser juzgado ni sentenciado sino por leyes dadas con anterioridad al hecho y exactamente aplicadas a él por el tribunal que previamente haya establecido la ley" (énfasis añadido). ${ }^{8} \mathrm{De}$ acuerdo con Fix Zamudio, la Corte de aquel tiempo entendió que la palabra "exactamente" significaba "indebidamente", por lo que concluyó que la inexacta aplicación de la ley ordinaria suponía una violación constitucional. ${ }^{9}$ En palabras de Fix Zamudio:

[C]uando un juez de cualquier jerarquía, de la esfera federal o de carácter local aplicara 'inexactamente' (es decir, indebidamente), un precepto legal secundario en un proceso concreto, por ese hecho infringía ese precepto constitucional [el 14] y por lo tanto 'violaba una garantía individual', lo que determinó que la propia Corte llegara a concentrar por conducto del juicio de amparo contra resoluciones judiciales, todas las sentencias de todos los jueces y tribunales del país. ${ }^{10}$

8 El caso es conocido como Amparo Vega, y fue resuelto por la Corte el 29 de abril de 1869. Manuel Vega — un juez de Mazatlán al que se le había sido suspendido en el ejercicio profesional de abogado, como sanción por haber dictado sentencias contra el texto expreso de la ley- promovió un juicio de amparo por considerar injustificada la sanción (no estaba contemplada como tal, ya que a su conducta habría correspondido una suspensión o la destitución como juez, pero no la inhabilitación para ejercer como abogado). El juez de distrito negó el amparo, debido a que el artículo 8 de la Ley vigente prohibía la procedencia del juicio en asuntos judiciales. La SCJN revisó el fallo y lo revocó, concediendo el amparo a Manuel Vega. Cfr. González Oropeza, Manuel, "El amparo en negocios judiciales. El caso de Manuel Vega", Anuario Mexicano de Historia del Derecho, vol. X, México, 1998, pp. 394 y 395. De acuerdo con los expertos, la sentencia fue muy escueta y mal fundamentada; tanto, que desató un debate político, que conminaría a la Corte a enviar un informe al Congreso, en el que se vio obligada a explicar que, a su juicio, el artículo 8 de la Ley de Amparo era inconstitucional, porque desconocía el contenido de los artículos 101 y 102 de la misma Ley, según los cuales el amparo era procedente contra todo acto o ley de cualquier autoridad que infringiera las "garantías individuales", por lo que no podían quedar excluidas las decisiones judiciales. Cfr. Fix Zamudio, Héctor, "El amparo mexicano como instrumento protector de los derechos humanos", cit., p. 258.

9 Un lector atento puede entender que lo que el constituyente de 1857 prescribió en esta disposición fue el respeto al principio de taxatividad (o legalidad) en materia penal (lex certa), que consiste en la prohibición de que se impongan penas por conductas que no están estrictamente (exactamente) contempladas como delitos.

10 Fix-Zamudio, Héctor, "El amparo mexicano como instrumento protector de los derechos humanos", cit., pp. 256 y 257. 
De este modo, el llamado amparo casación (o amparo judicial, que después se llamaría directo) nació con la única finalidad de controlar constitucionalmente la actividad judicial. Sin embargo, dado que lo que se controlaba era la "inexacta" o "indebida" aplicación de la ley, empezó a ser llamado "control de legalidad". De aquí parte una confusión que sorprende a propios y extraños cuando se escuchan o se leen frases como "ese asunto no es de constitucionalidad, porque en él únicamente se violaron los artículos 14 y 16 de la Constitución”, como si tal afirmación fuera lógicamente posible.

Volviendo a la historia, son bien conocidos los vaticinios de Rabasa con respecto a lo que él consideró un desafortunado error interpretativo del artículo 14 de la Constitución de 1857, a cargo de la SCJN. ${ }^{11}$ De manera particular, vaticinó que la Corte sufriría un desprestigio derivado, entre otros factores, del enorme rezago que se generaría. La historia le dio la razón en ese aspecto: la Corte se sobresaturó de asuntos, porque se convirtió en la última instancia de prácticamente todos los juicios celebrados a lo largo y ancho del país; sin embargo, el amparo judicial continuó.

En el Congreso Constituyente de 1917 se planteó revertir esta situación, pero no se logró. ${ }^{12}$ A lo largo del siglo XX, el número de asuntos continuó creciendo al tiempo en que lo hizo la Corte, que pasó de once a dieciséis ministros en 1928, y de dieciséis a veintiuno en 1934. Para 1951 fue necesario establecer una Sala Auxiliar, con cinco ministros supernumerarios. En ese mismo año se crearon los primeros tribunales colegiados de circuito precisamente para paliar el rezago, a los que se transfirió la competencia para conocer de los amparos directos; sin embargo, tampoco fue suficiente.

La reforma constitucional de 1967 supuso un importante esfuerzo para disminuir la carga de la SCJN, ya que a partir de entonces ésta dejó de ser competente para conocer los amparos directos, y se quedó solamente con una pequeña parte: ciertos asuntos sociales y económicos trascendentes. Un segundo esfuerzo se llevó a cabo con la reforma constitucional de

11 Rabasa, Emilio, El artículo 14 y el juicio constitucional, cit., p. 123.

12 Fix-Fierro, Héctor, "El amparo judicial y la «imposible tarea» del Poder Judicial de la Federación. Perspectivas en el centenario de la Constitución de Querétaro", en Ferrer Mac-Gregor, Eduardo y Herrera García, Alfonso (coords.), El juicio de amparo en el centenario de la Constitución mexicana de 1917, t. I, México, UNAM, Instituto de Investigaciones Jurídicas, 2017, p. 484. 
1987-1988, mediante la cual se delegó definitivamente toda la competencia a los tribuales colegiados de circuito. Fue entonces cuando se estableció que la Corte sólo debía resolver temas de constitucionalidad, puesto que los de legalidad quedaban reservados a los tribunales colegiados. ${ }^{13}$ ¿Cuáles eran estos temas? ¿Qué se dejó a la Corte y qué a los tribunales colegiados?

A los tribunales colegiados se les otorgó en definitiva la competencia para resolver prácticamente todos los temas de legalidad ${ }^{14}$ mediante el amparo directo, mientras que a la SCJN se le permitió revisar, en una segunda instancia extraordinaria, algunos de esos amparos que tuvieran ciertas características, a saber: aquellos en los que se hubiera reclamado la constitucionalidad de una norma general, así como aquellos en los que los nuevos tribunales colegiados realizaran interpretaciones directas de la Constitución. Es en este momento cuando nacen las cuestiones "propiamente constitucionales".

Así las cosas, no es que los problemas que se resuelven mediante el amparo judicial o directo no sean temas constitucionales; lo son, porque el parámetro de control se encuentra en la Constitución (especialmente en los artículos 14 y 16); sin embargo, se les llama "amparos de legalidad" porque históricamente se ha utilizado este término para designar un tipo muy especial de control constitucional: el relacionado con la exacta aplicación de la ley.

Por ello, las confusiones que se dan en la práctica a la hora de determinar si un determinado recurso de revisión en amparo directo debe o no ser considerado como procedente se derivan de la ambigüedad de término legalidad, que puede significar dos cosas muy diferentes: 1) legalidad como conformidad $^{15}$ de una determinada conducta con lo descrito en una ley, y

\footnotetext{
13 Ibidem, p. 486.
}

14 Existe otro mecanismo adicional mediante el cual la SCJN podría revisar casos de legalidad: la facultad de atracción prevista en el artículo 40 de la Ley de Amparo. Por desgracia, no resulta en absoluto extraño que en el juicio de amparo mexicano existan tantas y tan variadas excepciones (y excepciones de las excepciones); de ahí que se le considere como uno de los procesos más complcados y engorrosos de la región. Cfr. Pou Giménez, Francisca, "El nuevo amparo mexicano y la protección de los derechos: ¿ni tan nuevo ni tan protector?", Anuario de Derechos Humanos, Santiago, Centro de Derechos Humanos de la Facultad de Derecho de la Universidad de Chile, 2014, p. 93.

15 El término legalidad es ambiguo, ya que puede ser entendido, al menos, en tres sentidos distintos: a) como criterio clasificatorio, es decir, como una propiedad que comparten todos los entes jurídicos: instituciones, actos, eventos, funcionarios y textos ("Si 
2) legalidad como violación constitucional derivada de una incorrecta adjudicación, que tiene como consecuencia la violación de algunas normas constitucionales (especialmente los artículos 14 y 16, aunque pueden ser otros).

Si esto es así, entonces ¿qué se decide realmente a la hora de resolver la procedencia de un recurso de amparo directo? La respuesta a la pregunta es que, siguiendo el mandato constitucional y legal, la SCJN debe analizar cada recurso de revisión y descartar aquellos que sean de legalidad en cualquiera de los dos sentidos señalados. Y más aún: pueden descartar otros que sean realmente de constitucionalidad, pero que no considere importantes y trascendentes, como hemos ido señalando.

En suma, la reforma constitucional de 1987-1988 no inventó el control de legalidad (que es en realidad un tipo de constitucionalidad), pues éste viene de antiguo ligado al amparo casación; más bien la reforma creó un nuevo tipo de constitucionalidad: las cuestiones propiamente constitucionales.

El siguiente esquema, con sugerencias terminológicas, podría ayudar a entenderlo mejor (elaboración propia):

$\mathrm{X}$ está regulado por la ley, entonces X es legal"); b) como conformidad, es decir, como criterio para determinar si un determinado acto ha sido emitido de acuerdo con el derecho ("el acto X es legal porque es conforme a derecho"), y c) como valor o principio, esto es, como uno de los pilares del Estado de derecho bajo el cual deben actuar los titulares del poder ("el funcionario Y debe conducirse dentro de los márgenes de la legalidad"). Cfr. Shapiro, Scott, Legality, The Belknap Press of Harvard University Press, traducción castellana de Diego M. Papayannis y Lorena Ramírez Ludeña, Legalidad, Madrid, Marcial Pons, 2011, pp. 23 y 24. 


\section{Cuadro 1 \\ LEGALIDAD Y CONSTITUCIONALIDAD COMO CUESTIONES \\ EN EL AMPARO}

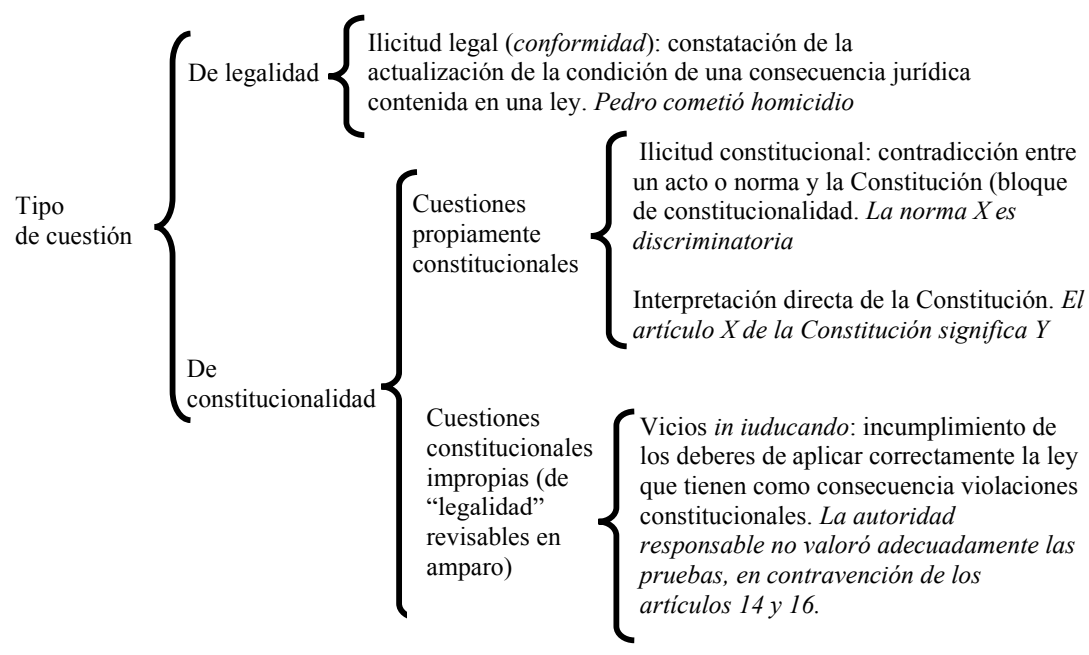

Como puede verse, la palabra legalidad es ambigua, ya que, por un lado, se usa para designar aquellas cuestiones que se resuelven mediante el contraste entre un hecho determinado y un supuesto jurídico contenido en una disposición legal, con la finalidad de establecer la consecuencia jurídica correspondiente; mientras que, por otro lado, se usa para designar los vicios in iudicando, propios de la casación que suponen, indirectamente, cierto tipo de violaciones constitucionales.

Ante este panorama, y dado que se ha buscado consolidar a la SCJN como un auténtico tribunal constitucional, se han hecho esfuerzos a nivel constitucional y legal para que la Corte no resuelva cuestiones de legalidad, que son en realidad constitucionales, pero no en sentido propio. De ahí que tenga sentido la distinción tan conocida entre cuestiones propiamente constitucionales y cuestiones de legalidad (cuestiones constitucionales impropias).

En suma, la SCJN es legalmente competente para decidir cuándo un recurso de revisión es procedente y cuándo no, para lo cual ha de resolver previamente si el caso es de legalidad o de constitucionalidad en los tér- 
minos expuestos. Sin embargo, la infraestructura legal con la que cuenta para realizar semejante juicio de valor le permite colocar lícitamente un mismo tipo de caso en uno u otro casillero, con lo cual es posible afirmar que el propio sistema hace posible el incumplimiento de la regla de justicia formal. Consecuentemente, este laxo sistema de selección de casos ha contribuido a que en México tengamos una auténtica frontera móvil entre legalidad y constitucionalidad, gracias a la cual los ministros pueden colocar un caso en el lado que les apetezca, sin que ello suponga ilicitud alguna. La movilidad de la frontera no es algo baladí, ya que se generan dos tipos de situaciones. La primera es que la SCJN, de hecho, resuelve asuntos que puede, pero no debería resolver, con lo cual se aleja de la aspiración de consolidarse como un auténtico tribunal constitucional. La segunda es que, al desechar casos que no debiera haber desechado, cumple con una regla, pero desconoce un principio: el de igualdad. ${ }^{16}$

\section{UNA FRONTERA MÓVIL EN LA JURISPRUDENCIA MEXICANA}

De un universo acotado, pero suficientemente orientador, de criterios contenidos en el Semanario Judicial de la Federación, relativos al amparo directo en revisión, específicamente la novena época y lo que va de la décima, pude detectar que, al interpretar los conceptos de legalidad, constitucionalidad e importancia y trascendencia, la SCJN ha construido las siguientes cuatro categorías: ${ }^{17}$ a) cuestiones de "mera legalidad"; b) cues-

16 En efecto, cualquier decisión comprendida en ese marco (procedencia/improcedencia) está prima facie permitida. No obstante, cuando la movilidad de la frontera entre legalidad y constitucionalidad genera tratos desiguales injustificados entre los quejosos, entonces podemos estar asistiendo a lo que Manuel Atienza y Juan Ruiz Manero llaman "ilícito atípico", concretamente un "fraude a la ley". De acuerdo con ellos, el fraude a la ley tiene lugar cuando una conducta que aparentemente es conforme a una norma ("norma de cobertura"), produce en realidad un resultado contrario a otra norma ("norma defraudada"), que siempre es un principio. Así, en nuestro caso, la conducta de la SCJN aparentemente es conforme a los artículos 107, fracción IX, de la Constitución; 81, fracción II, de la Ley de Amparo y el Acuerdo General 9/2015; sin embargo, un caso es calificado como procedente y otro del mismo tipo como improcedente, se viola el principio de igualdad. Atienza, Manuel y Ruiz Manero, Juan, Ilícitos atípicos, Madrid, Trotta, 2000, pp. 74 y 75.

17 He construido estas categorías a partir de mi experiencia como secretario de estudio y cuenta en la SCJN. No pretendo exhaustividad, sino claridad. He delimitado esta investigación a la novena y a la décima épocas de la jurisprudencia porque puedo analizar 
tiones "propiamente constitucionales"; c) cuestiones que, siendo prima facie constitucionales, terminan siendo de legalidad (las llamaré "cuestiones de legalidad forzada"), y d) cuestiones que, siendo prima facie de legalidad, terminan siendo constitucionales (las llamaré "cuestiones de constitucionalidad forzada").

El método de búsqueda que utilicé fue en realidad muy sencillo y rudimentario: en el motor de búsqueda del Semanario Judicial de la Federación tecleé frases como "legalidad", "constitucionalidad", "improcedente", "agravios inoperantes", entre otras. En total, detecté 44 criterios: catorce tesis de jurisprudencia y treinta tesis aisladas, que pude clasificar en las cuatro categorías mencionadas. Una vez organizada la información, me di a la tarea de construir el siguiente cuadro, que muestra la distribución de los criterios detectados en función de dos variables: 1) el órgano emisor, y 2) si se trata de un criterio aislado (TA) o de una jurisprudencia obligatoria (J). De este modo, se muestra cuántos criterios aislados y cuántos de jurisprudencia fueron detectados por cada una de las Salas y por el tribunal pleno:

\section{Cuadro 2}

DISTRIBUCIÓN DE TESIS A PARTIR DE LOS CRITERIOS

DE LEGALIDAD Y CONSTITUCIONALIDAD

\begin{tabular}{|l|c|c|c|c|c|c|c|c|c|}
\hline \multicolumn{1}{|c|}{ Categoría } & \multicolumn{2}{c|}{$\begin{array}{c}\text { Primera } \\
\text { Sala }\end{array}$} & \multicolumn{2}{c|}{$\begin{array}{c}\text { Segunda } \\
\text { Sala }\end{array}$} & \multicolumn{2}{c|}{ Pleno } & \multicolumn{3}{c|}{ Total } \\
\hline & $\mathrm{J}$ & TA & $\mathrm{J}$ & TA & J & TA & J & TA & Total \\
\hline Mera legalidad & 2 & 9 & 0 & 1 & 1 & 1 & 3 & 11 & 14 \\
\hline $\begin{array}{l}\text { Propiamente } \\
\text { constitucionales }\end{array}$ & 1 & 1 & 2 & 1 & 1 & 0 & 4 & 2 & 6 \\
\hline Legalidad forzada & 2 & 3 & 1 & 1 & 0 & 1 & 3 & 5 & 8 \\
\hline $\begin{array}{l}\text { Constitucionalidad } \\
\text { forzada }\end{array}$ & 2 & 6 & 1 & 4 & 1 & 2 & 4 & 12 & 16 \\
\hline Total & 7 & 19 & 4 & 7 & 3 & 4 & 14 & 30 & 44 \\
\hline $\begin{array}{l}\text { Fuente: elaboración propia. } \\
\text { Nota: J = jurisprudencia; TA = tesis aislada. }\end{array}$
\end{tabular}

con mayor facilidad este segmento del tiempo, que, además, coincide parcialmente con mi experiencia práctica.

Esta obra está bajo una Licencia Creative Commons

Atribución-NoComercial-SinDerivar 4.0 Internacional, IIJ-UNAM. 
¿Qué nos dicen estos datos? En principio, se advierte una mayor actividad de la Primera Sala en la emisión de los criterios sobre ambas cuestiones. La primera sala, además, es la que emite mayores criterios "forzados" en uno y otro sentido. Por su parte, la Segunda Sala, aunque presenta una "actividad" menor, se inclina sobre todo forzar la constitucionalidad, inclinación que también se nota en la Primera.

Si indagamos más profundamente, los datos nos dicen mucho más. Los catorce ejemplos de la mera legalidad ${ }^{18}$ demuestran cómo la Corte parecía estar invirtiendo su energía en detectar casos para desecharlos, sin hacer demasiado esfuerzo para determinar si en algún aspecto merecía la pena admitirlo. Los ocho casos de legalidad forzada confirman este diagnóstico. ${ }^{19}$

En la tesis aislada 1a. CLXXXIX/2016 (10a.), por ejemplo, la propia SCJN consideró que para determinar la procedencia del recurso el énfasis no se coloca ni en la interpretación directa ni en la presunta inconstitucionalidad de una norma general, sino en que los casos sean relevantes y trascendentes para el orden nacional. El rubro de la tesis es: "Revisión en amparo directo. Si al analizar su procedencia se advierte que con la resolución del recurso no se fijará un criterio de importancia y trascendencia, debe desecharse aunque se actualice hipotéticamente una cuestión constitucional". En esencia, la Primera Sala señala que una cuestión constitucional no es más que "un requisito técnico" cuyo control debe obviarse si no resulta ni importante ni trascendente. Asimismo, sostiene que la centralidad de las notas de importancia y trascendencia se fundamenta en la "determinación del Constituyente de reservar la decisión de la admisión del recurso a un ámbito de política judicial de la Corte" (énfasis añadido).

18 Los catorce criterios de mera legalidad son los siguientes: 1a./J. 13/2017 (10a.); 1a./J. 1/2015 (10a); 1a./J. 56/2007; 1a. LIX/2009; 1a. CCXLV/2011 (9a); 1a. CCCXXI/2013 (10a); 1a. CLXXXVII/2014 (10a.); 1a. CXIV/2016 (10a); 1a. CXIV/2016 (10a); 1a. CCCXXVIII/2014 (10a); 1a. CLXXXVII/2014 (10a); 2a. 1/97; P./J. 34/98; y P. IV/2017 (10a.). Lo que tienen en común todos estos criterios queda representado por la tesis aislada 1a. CXIV/2016 (10a.), de rubro "Amparo directo en revisión. Entre las cuestiones de legalidad que lo hacen improcedente, se encuentran las referidas a la indebida valoración de pruebas, la acreditación de los elementos del tipo penal y lo relativo a la individualización de la pena". Sucintamente, el criterio dice que las argumentaciones referidas a la indebida valoración de pruebas, la acreditación de los elementos del tipo penal y la individualización de la pena, son cuestiones de mera legalidad.

19 Los ocho casos de legalidad forzada son los siguientes; 1a./J. 103/2011; 1a./J. 13/2017 (10a.); 1a. CLXXXIX/2016 (10a.); 1a. LIII/2011; 1a. LXIX/2015 (10a.); 2a./J. 5/2013 (10a.); 2a. LVIII/2014 (10a.); y P. XLV/2007. 
Lo interesante y al mismo tiempo cuestionable de este criterio es que establece un permiso fuerte para convertir un caso de constitucionalidad en uno de legalidad. Con ello, los ministros se autorizan a sí mismos a tener por justificada una determinada decisión de procedencia con base en criterios más políticos que jurídicos. Lo paradójico es que este permiso jurisprudencial juridifica la posibilidad de utilizar razones políticas para admitir o desechar un determinado recurso. Con semejante liberalidad, la Corte perfectamente podría utilizar este criterio para deshacerse de recursos indeseables o incómodos, aun cuando se tratara de genuinos casos de constitucionalidad, al menos en cuanto a lo que aquí he llamado "requisitos conceptuales". El requisito referido a la importancia y trascendencia (requisito discrecional) puede funcionar como salvoconducto político para evadir la responsabilidad de los ministros. Imaginemos "casos hipotéticos" en los que la Corte prefiera no pronunciarse sobre tortura o desaparición forzada, para evitar un conflicto político con el gobierno de turno. Esta tendencia al desechamiento se confirma si contrastamos las cifras de mera legalidad y legalidad forzada, que en conjunto suman veintidós asuntos, contra los escasos seis casos de la categoría cuestiones propiamente constitucionales. ${ }^{20}$

En contraste con lo anterior, en la categoría de constitucionalidad for$z a d a$ encontramos quince casos, ${ }^{21}$ en los que se advierte el rompimiento de paradigmas llevado a cabo por algunos ministros audaces que entendieron mejor el nuevo carácter de la Corte como tribunal constitucional y no sólo admitieron, sino resolvieron de fondo importantes asuntos en materia de derechos humanos (algunos de ellos, derechos sociales) mediante el juicio de amparo directo en revisión e, incluso, mediante el amparo indirecto. ${ }^{22}$

20 Los seis casos de cuestiones propiamente constitucionales son los siguientes: 1a./J. 64/2014 (10a.); 1a. CCCIII/2014 (10a.); 2a./J. 46/98; 2a./J. 114/2006; 2a. XXXIV/2007; y P./J. 71/2009.

21 Los dieciséis casos de constitucionalidad forzada son los siguientes: 1a. CXCVIII/2018 (10a.); 1a./J. 8/2012; 1a./J. 80/2010; 1a. XXI/2010; 1a. XLIX/2010; 1a. XIX/2010; 1a. CCCLXIX/2013 (10a.); 1a. XXXVI/2016 (10a.); 2a./J. 114/2018; 2a. LXXXII/2016 (10a.); 2a. IX/2014; 2a. LXXII/2019; 2a. IXI/2013 (10a.); P./J. 22/2014 (10a.); P. LXXVII/2000; y P III/2002.

22 Los siguientes casos son ejemplos de amparos que fueron resueltos por la Corte, antes de la reforma constitucional de 2011, con un perfil de auténtico tribunal constitucional y no de mera casación: 1) ADR 935/2006, "caso Barajas", sobre mayoría de edad penal; 2) AD 6/2008, "caso Transexual", sobre derecho a la no discriminación"; 3) ADR 2044/2008, “caso Acámbaro", sobre libertad de expresión; 4) ADR 1492/2007, "caso 
En estos asuntos es posible advertir interpretaciones que van más allá de los textos legales con componentes de derecho internacional de los derechos humanos, incluso antes de la reforma de 2011.

Una vez implementada esa reforma, la cultura litigiosa en el país cambió, y la forma de tocar las puertas de la Corte dio un giro de 180 grados, porque para impugnar la violación de algún derecho se dejó de utilizar de forma predominante el cajón de sastre en el que se habían convertido los artículos 14 y 16 constitucionales. Fue entonces cuando nos fuimos al otro extremo: prácticamente cualquier tipo de asunto es presentado como un tema de constitucionalidad, aunque realmente no lo sea; por ejemplo, cuestiones relacionadas con la constitución de sociedades mercantiles, la firma de un contrato privado, una acción reivindicatoria, etcétera ${ }^{23}$ (temas de legalidad en el sentido de conformidad). ${ }^{24}$

La Corte - especialmente la Primera Sala, dedicada a los asuntos civiles y penales - había abierto sus puertas — quizá demasiado — a la procedencia de prácticamente cualquier tipo de asunto. Una de las consecuencias de esta situación fue el alud de amparos que incrementó de manera significativa el número de casos: entre 2009 y 2016, el número de asuntos resueltos pasó de 4,000 a 16,139; es decir, el número se multiplicó por cuatro, de los cuales un alto porcentaje corresponde a amparos directos en revisión. ${ }^{25}$

Un buen ejemplo de esta apertura es la jurisprudencia P./J. 22/2014 (10a.), clasificada en este trabajo como "constitucionalidad forzada", cuyo

Toxicómanos", sobre derecho a la salud, y 5) AD 912/2008, “caso Acteal", sobre derecho a la libertad personal". Incluso, en amparo indirecto, la Corte mostró esa apertura, al resolver los siguientes casos: 1) AR 2676/2003, "caso Bandera", sobre libertad de expresión; y 2) AR 2146/2005, "caso Militares con VIH”, cobre derecho a la salud y a la no discriminación.

23 Existe un caso paradigmático en el cual se resolvió un amparo derivado de la nulidad de un contrato de promesa de compraventa de un departamento de lujo en una playa del estado de Jalisco. El derecho alegado como violado fue el "derecho a una vivienda digna", porque el departamento no tenía ventanas con vista al mar en una de las habitaciones. La SCJN consideró que el ADR era procedente, y resolvió centralmente el problema, consistente en determinar si el derecho social a una vivienda digna se debe o no aplicar a una vivienda de lujo. La Corte concedió el amparo.

24 Shapiro, Scott, Legalidad, cit. Véase también el cuadro 1, supra.

25 SCJN, Informe Anual de Labores, presentado por el ministro presidente, Luis María Aguilar Morales en diciembre de 2016. Publicación en línea: https://www.scjn.gob. $\mathrm{mx} /$ sites/default/files/informe_labores_transparencia/version/2016-12/INFORME\%20 MINISTRO\%20PRESIDENTE\%202016.pdf, pp. 12 у 13. 
rubro es: "CUESTIÓN CONSTITUCIONAL. PARA EFECTOS DE LA PROCEDENCIA DEL RECURSO DE REVISIÓN EN AMPARO DIRECTO, SE SURTE CUANDO SU MATERIA VERSA SOBRE LA COLISIÓN ENTRE UNA LEY SECUNDARIA Y UN TRATADO INTERNACIONAL, O LA INTERPRETACIÓN DE UNA NORMA DE FUENTE CONVENCIONAL, Y SE ADVIERTA PRIMA FACIE QUE EXISTE UN DERECHO HUMANO EN JUEGO". En este asunto, la Sala determinó que cuando se presente una colisión de este tipo, y sea necesario fijar el sentido de un derecho humano para resolverla, entonces debe concluirse que sí existe una cuestión propiamente constitucional. Lo anterior, porque detrás de esa operación subyace un juicio de "relevancia jurídica" fundado en la idea de coherencia normativa; de este modo, es necesario "...verificar la coherencia del orden constitucional como una unidad dotada de sentido protector o promocional de los derechos humanos, el cual se remite a argumentos sustanciales y no a razonamientos de índole formal".

En el mismo sentido, la tesis aislada 1a. CXCVIII/2018 (10a.) es un buen ejemplo de constitucionalidad forzada, ya que admite la procedencia sin tomar en cuenta los requisitos constitucionales y legales; en su lugar, la Sala, admitiendo que no hay fundamento legal para ello, incorpora los instrumentos de sotf law como parámetro de admisibilidad. El rubro de la tesis es "REVISIÓn EN AMPARO DIRECTO. PROCEDE EL RECURSO SI EN LA SENTENCIA RECURRIDA SE APLICARON INSTRUMENTOS NORMATIVOS DE «SOFT LAW» PARA INTERPRETAR EL CONTENIDO DE UN DERECHO HUMANO DE RANGO CONSTITUCIONAL". En síntesis, la Sala sostiene que, aunque tales instrumentos no forman parte del parámetro de control de regularidad constitucional, ello no impide que su contenido pueda ser empleado como un "...criterio orientador en sentido amplio, al tratarse de una doctrina especializada desarrollada por un organismo internacional de derechos humanos". De este modo, cuando el tribunal colegiado lleva a cabo un ejercicio de este tipo, tal actividad debe ser calificada como “... una interpretación directa de la Constitución para efectos de la procedencia del recurso de revisión en los juicios de amparo directo, no por el valor jurídico del instrumento mismo, sino por el impacto que tuvo en la decisión de un órgano jurisdiccional al momento de resolver un asunto".

Si hacemos un balance de lo anterior, podemos decir que la Corte mexicana ha incurrido en ciertas inconsistencias a la hora de resolver la procedencia de algunos recursos de revisión en el amparo directo, sin que ello suponga, en principio, violar la ley. El uso discrecional de las 
categorías que hemos detectado, aunque fueron propuestas con arreglo a reglas válidas y con el fin legítimo de mantener las competencias constitucionales de la SCJN, no deja de levantar sospechas de sesgo a cargo de los ministros.

En uno de los extremos, podemos apreciar que mediante el abuso del requisito discrecional (importancia y trascendencia) se puede disminuir la brecha de la constitucionalidad y, por ende, ensanchar la de la legalidad; en el otro extremo se produce el efecto contrario: al abusar de los criterios conceptuales (constitucionalidad de normas generales o interpretación directa de algún precepto constitucional), se disminuye la brecha de la legalidad y se ensancha la de constitucionalidad. De este modo, la SCJN termina convirtiendo problemas de simple adjudicación legal en complejos y enredados casos en los que se mezclan fuentes nacionales e internacionales y se ensayan estrategias como el test de proporcionalidad, derecho comparado, y todo lo que pueda sonar interesante o novedoso. Con ello, se olvida que un problema simple demanda una solución simple; que la argumentación persigue el fin de resolver problemas de forma sencilla, y que complicar un asunto no es un signo de buena salud argumentativa.

No me preocupa tanto el hecho de que este juego de significados provoque que varios casos terminen constitucionalizándose (a final de cuentas es eso lo que pretende la constitucionalización), sino que se viole la regla de justicia formal, al no otorgarse un trato igual a los seres pertenecientes a una misma categoría, ya que es posible que dos quejosos interpongan un mismo tipo de recurso y uno de ellos caiga en el terreno de la legalidad y el otro en el de la constitucionalidad, debido a que, por ejemplo, el segundo estuvo en mejores condiciones políticas para lograrlo. ${ }^{26}$

Asimismo, no es deseable que la Corte siga resolviendo casos que no debería resolver, porque, como he sostenido, con ello se aleja de la aspiración de consolidarse como un auténtico tribunal constitucional, y tampoco lo es que deje de resolver asuntos que debía resolver, ya que con ello incumple su misión como tribunal protector de derechos o defensor de la Constitución.

26 Infra, apartado V, punto 2. Razones políticas.

Esta obra está bajo una Licencia Creative Commons Atribución-NoComercial-SinDerivar 4.0 Internacional, IIJ-UNAM. 


\section{RASTREANDO LAS CAUSAS QUE EXPLICAN \\ EL FENÓMENO}

\section{El comportamiento de los ministros asociado a su concepción del derecho}

La actuación de los ministros refleja alguna preferencia teórica en cuanto a su concepción del derecho, y ello no tiene nada de particular, ya que no todos los operadores jurídicos lo entienden de la misma forma. ¿Es posible asociar alguna concepción del derecho con la actitud de los operadores jurídicos cuando hablamos de legalidad y constitucionalidad en los términos de este trabajo? A mi juicio, existen buenas razones para responder afirmativamente esta pregunta bajo los rubros del formalismo jurídico y el activismo judicial, entendidos a la manera de Manuel Atienza:

Por formalismo estoy entendiendo una concepción que ve el Derecho única o muy preferentemente como un conjunto de reglas y que rechaza interpretar las normas acudiendo a lo que son sus razones subyacentes. La desviación consiste por ello en prescindir de los fines y valores que dan sentido a la práctica jurídica (al para qué interpretar).

Y el activismo se caracteriza por ver en el Derecho únicamente esta última dimensión (valorativa), dejando pues de lado que el Derecho es también una práctica autoritativa, en la que las reglas juegan un papel esencial. La desviación consiste aquí en prescindir de los medios, de las formas; en no tomar en cuenta que si la interpretación es tan relevante en el Derecho, ello se debe precisamente al papel que juega en él la autoridad (donde no hay autoridades, como ocurre en el caso de la moral — la moral no heterónoma-, la necesidad de interpretación prácticamente desaparece). ${ }^{27}$

Considero que no sería muy descabellado afirmar que, al menos en los casos en los que se detectaron excesos, es posible clasificar a los ministros de la SCJN en alguna de esas dos categorías. Así, los ministros que, abusando de la discrecionalidad, se sienten más cómodos convirtiendo casos de legalidad en casos de constitucionalidad pueden asociarse, sin generalizar, con el activismo; mientras que los que — también abusando

27 Atienza, Manuel, "Siete tesis sobre activismo judicial", tesis quinta, en http://lamiradadepeitho.blogspot.com/2018/10/siete-tesis-sobre-el-activismo-judicial.html. 
de la discrecionalidad - prefieren realizar la conversión inversa podrían asociarse con el formalismo.

Afirmo lo anterior, porque para el primer grupo de ministros la función del tribunal constitucional consiste precisamente en ensanchar el terreno de la constitucionalidad aprovechando la ductilidad del derecho, en pro de los derechos humanos y de los fines que persigue el llamado constitucionalismo. ${ }^{28}$ Por su parte, el segundo grupo tiende a colocar más casos en el terreno de la legalidad, porque supone que lo correcto es ceñirse a la aplicación de las fuentes formales del derecho, como la mejor garantía para preservar el orden jurídico, mediante la salvaguarda de los principios de seguridad y certeza jurídicas; asimismo, consideran como valioso reducir al mínimo el margen de discrecionalidad del juzgador o, en su defecto, utilizar esa discrecionalidad para transformar casos de constitucionalidad en casos de legalidad.

Con todo, es más sencillo detectar las credenciales teóricas de un jurista teórico que las de un jurista práctico, porque algunos de estos últimos o no tienen una clara conciencia de lo que significa ser, por ejemplo, formalista o activista, o bien sencillamente prefieren no hacerla explícita. Naturalmente, no pretendo generalizar, porque hay jueces, magistrados y ministros que también son académicos, y en algunos casos excepcionales llegan a tener más conciencia teórica que algunos colegas de la academia.

La falta de conciencia teórica, a su vez, se explica en gran medida por la deficiente formación y capacitación que por lo general tienen los opera-

28 Soy consciente de la ambigüedad del término "constitucionalismo", pero no es mi propósito despejarla en este trabajo. Optaré por el significado sugerido por Manuel Atienza, para quien se trata de una nueva concepción del derecho, cuyas principales notas características serían las siguientes: a) el derecho no es una realidad ya dada, sino una práctica social compleja que incorpora una pretensión de corrección o justificación; b) supone una mayor demanda de argumentación; c) implica cierto objetivismo valorativo; d) la interpretación debe ser entendida más como actividad que como producto; e) supone otorgar cierta prioridad al elemento valorativo del derecho sobre el autoritativo, y f) el razonamiento jurídico no puede ser insular, ya que tiene un componente moral y político, sin que estas tres esferas lleguen a confundirse. Atienza, Manuel, Curso de argumentación jurídica, Madrid, Trotta, 2013, pp. 29 y 30. Para no confundirlo con el "neoconstitucionalismo", véase Atienza, Manuel, "Ni positivismo jurídico ni neoconstitucionalismo. Una defensa del constitucionalismo postpositivista", Revista Argentina de Teoría Jurídica, Argentina, Universidad Torcuato di Tella, vol. 15, núm. 2, diciembre 2014, pp. 194 y ss. Asimismo, véase Pozzolo, Susana, "Neoconstitucionalismo y especificidad de la interpretación constitucional”, Doxa. Cuadernos de Filosofía del Derecho, núm. 21, vol. II, España, Universidad de Alicante, pp. 339-354.

Esta obra está bajo una Licencia Creative Commons Atribución-NoComercial-SinDerivar 4.0 Internacional, IIJ-UNAM. 
dores judiciales y sus equipos, con honrosas excepciones. La capacitación judicial de nuestros tiempos implica una orientación muy distinta a la de los programas tradicionales de formación jurídica basados exclusivamente en la memorización de textos y procedimientos, lo que contribuye a la perpetuación del formalismo. ${ }^{29} \mathrm{~A}$ mi juicio, conviene sembrar en los juristas prácticos una conciencia teórica que les permita entender mejor cuáles son los fines últimos de la práctica jurídica. Con una adecuada conciencia teórica podrían matizarse los excesos del formalismo y el activismo, y con ello podrían reconocerse en su justa dimensión los casos de legalidad y los de constitucionalidad. De este modo, la "legalidad forzada" y la "constitucionalidad forzada" no tendrían que ser categorías autónomas, sino más bien, casos aislados y excepcionalmente difíciles.

\section{Razones políticas}

No puedo dejar de mencionar que existen razones extrasistemáticas -que son las más preocupantes-, que influyen decididamente en el movimiento de la frontera entre legalidad y constitucionalidad. En México no es trivial que un amparo directo en revisión resulte procedente y, por ende, sea revisado por la Suprema Corte de Justicia de la Nación. La procedencia supone, por decir lo menos, un triunfo para los litigantes (que tendrán una buena razón para aumentar sus honorarios), aun cuando el asunto se pierda en el fondo.

Asimismo, la procedencia del recurso abre la posibilidad de cabildeo, es decir, de que los abogados accedan de manera informal a las oficinas de algunos ministros a "preguntar por su asunto". No es extraño ver por los pasillos de la Suprema Corte a litigantes, autoridades administrativas, militares y público en general solicitando "audiencia" a los ministros (situación que, dicho sea de paso no está — pero debería estar - prevista por la ley). Esta práctica se conoce como "alegato de oreja". ${ }^{30}$

Desgraciadamente, esta práctica está tan generalizada en la SCJN, ${ }^{31}$ que podríamos calificarla como "normal", ya que a casi nadie parece extrañarle,

\footnotetext{
29 Atienza, Manuel, "Siete tesis sobre activismo judicial", cit., tesis sexta.

30 Mayer-Serra Carlos Elizondo y Magaloni, Ana Laura, "El «alegato de oreja», inequidad y mediocridad”, Boletín Mexicano de Derecho Comparado, México, 2015.

31 Mención aparte merece la Sala Superior del Tribunal Electoral del Poder Judicial de la Federación, la otra alta corte mexicana, en donde, en un clima de transparencia, 
ni se conocen oposiciones serias al respecto. Así, recibir periódicamente en sus oficinas a litigantes y autoridades forma parte de las agendas de los ministros. Con todo, el alegato de oreja no es algo que cualquiera pueda lograr con facilidad, ya que acceder a un ministro depende de "buenas relaciones", de tener contactos, influencias; en fin, depende de condiciones objetivas de poder. En este sentido, no es de extrañarse que algunos asuntos de legalidad sean "convertidos" artificiosamente en temas de constitucionalidad, o viceversa. Y, naturalmente, esto no depende ni de las instituciones procesales ni de las preferencias teóricas de los ministros, sino de una forma laxa de entender la independencia judicial.

En efecto, existen al menos tres formas de entender la independencia judicial: como conjunto de garantías institucionales indispensables para el adecuado ejercicio de la función jurisdiccional, ${ }^{32}$ como virtud judicial ${ }^{33} \mathrm{y}$ como deber. ${ }^{34}$ La primera de ellas es la que impera en México, y es, por decir lo menos, débil, cuando no evidentemente falsa. La carrera judicial, la irreductibilidad salarial o la inamovilidad de los jueces son ciertamente condiciones necesarias, pero no suficientes, para que el ejercicio de la jurisdicción sea realmente independiente. Este conjunto de condiciones constituye, en todo caso, el marco institucional adecuado para ejercer la independencia, pero no es, sin más, la independencia; se trata más bien del autogobierno de

las visitas de los litigantes se han formalizado como genuinas audiencias, en las que las partes (no una sola, como en la Corte) acuden a ver a los magistrados y sus equipos para discutir sobre el asunto.

32 La jurisprudencia mexicana ha acuñado esa definición a través de varias tesis. Por todas, véase la número P./J. 115/2009, del Tribunal Pleno de la Suprema Corte de Justicia de la Nación, en la que se distinguen las siguientes garantías: 1) la idoneidad en la designación de los jueces y magistrados; 2) la consagración de la carrera judicial; 3) la seguridad económica de jueces y magistrados (remuneración adecuada, irrenunciable e irreductible); 4) la estabilidad o seguridad en el ejercicio del cargo, que comprende: a) la determinación objetiva del tiempo de duración en el ejercicio del cargo; b) la posibilidad de ratificación, y c) la inamovilidad judicial para los que hayan sido ratificados, y 5) la autonomía de la gestión presupuestal.

33 De acuerdo con el artículo 2 del Código Modelo Iberoamericano de Ética Judicial, de 2006, "el juez independiente es aquel que determina desde el Derecho vigente la decisión justa, sin dejarse influir real o aparentemente por factores ajenos al Derecho mismo".

34 La independencia es un deber del juez correlativo al derecho de los ciudadanos a ser juzgados desde el derecho. Aguiló Regla, Josep, "Independencia e imparcialidad de los jueces y argumentación jurídica”, Isonomía, Revista de Teoría y Filosofía del Derecho, México, núm. 6, abril de 1997, pp. 75-77. 
los jueces. ${ }^{35}$ Por desgracia, un sector importante de la judicatura mexicana identifica la independencia con estas garantías a favor y en beneficio de los jueces, al grado de considerarlas como auténticos derechos. ${ }^{36}$

Resulta un tanto inquietante que en la jurisprudencia mexicana que, como se sabe, es obligatoria para los jueces, no se haya recogido el concepto de independencia judicial contenido tanto en el Código Iberoamericano de Ética Judicial como en los Principios de Bangalore sobre conducta judicial, ambos suscritos por la SCJN. En estos documentos la independencia se entiende como una exigencia moral a los jueces o como un auténtico deber. ${ }^{37}$ Desde mi punto de vista, estos documentos contienen una mejor concepción de independencia judicial, tanto por sus conceptos como por su carácter normativo; sin embargo, al tratarse de soft law no han logrado permear adecuadamente en la conducta de la mayoría de los jueces.

Considero que la SCJN tiene la gran oportunidad de convertir en hard law tales contenidos mediante su jurisprudencia obligatoria, que es seguida fielmente por los jueces. Naturalmente, una de las reglas concretas mediante las cuales se podría cristalizar el principio de independencia judicial sería la de prohibir las entrevistas informales con los ministros, sin la presencia de ambas partes. O bien podrían regularse tales visitas mediante pautas claras y respetuosas del equilibrio procesal y la igualdad

\footnotetext{
35 Idem.

36 Ejemplo de ello son los amparos promovidos, en tiempos recientes, por los jueces en contra de la posible reducción salarial. Si van al amparo, es poque consideran que la irreductibilidad salarial es un derecho. Véase, por ejemplo: https://www.jornada.com. $m x / 2018 / 11 / 22 /$ politica/014n2pol.

37 El Código Iberoamericano de Ética Judicial señala: "Los «principios éticos» configuran el repertorio de las exigencias nucleares de la excelencia judicial, pero como tales pueden justificar diferentes normas en donde se especifiquen distintas conductas en relación a determinadas circunstancias. Así, por ejemplo, la independencia es inequívocamente uno de esos «principios», y desde ella es posible delinear normas que, de manera más concreta, modalicen conductas exigibles". Cfr. Cumbre Judicial IberoamericanaComisión Iberoamericana de Ética Judicial, Código Iberoamericano de Ética Judicial, disponible en http://www.poderjudicial.es/cgpj/es/CIEJ/Codigo-Iberoamericano-de-EticaJudicial/, p. 6. Por su parte, en el artículo 1.1. de los Principios de Bangalore se establece: "Un juez deberá ejercer su función judicial de forma independiente, partiendo de su valoración de los hechos y en virtud de una comprensión consciente de la ley, libre de cualquier influencia ajena, de instigaciones, presiones, amenazas o interferencias, sean directas o indirectas, provenientes de cualquier fuente o por cualquier razón". Comentario relativo a los Principios de Bangalore sobre la conducta judicial, Viena, Oficina de las Naciones Unidas contra la Droga y el Delito, UNODC, 2013, p. 36.
} 
de armas en el proceso. Mientras esto no suceda, las influencias de carácter político seguirán incidiendo en el movimiento irregular de la frontera entre legalidad y constitucionalidad.

\section{CONCLUSIONES}

1. El primer hallazgo de este trabajo es que la importancia y trascendencia de un asunto es considerada por la propia legislación como condición necesaria y suficiente de la procedencia del recurso de revisión en el amparo directo, y no como debería de ser: que dicha condición fuera la constitucionalidad en sentido propio. En efecto, de conformidad con las reglas del sistema, no basta con que se acredite cualquiera de dos requisitos conceptuales (constitucionalidad de normas generales o la interpretación directa de la Constitución), sino que resulta necesario que además el caso revista el carácter de importante y trascendente (requisito discrecional). A final de cuentas, es este último requisito el que permite "mover la frontera" hacia el terreno que los ministros prefieran: la legalidad o la constitucionalidad.

De este modo, la procedencia del recurso de revisión en el amparo directo no depende en realidad de que el tema sea genuinamente constitucional, sino sobre todo de que el caso sea considerado por la SCJN como importante y trascendente. La vaguedad de estos conceptos permite que los operadores jurídicos ejerzan una enorme discrecionalidad a la hora de seleccionar los casos. Una de las consecuencias de dicha discrecionalidad es que mediante una profusa emisión de criterios de jurisprudencia y aislados en México se ha creado una auténtica frontera móvil entre la legalidad y la constitucionalidad.

2. Un segundo hallazgo tiene que ver con la ambigüedad del término "legalidad". En sus inicios, el amparo no procedía en contra de sentencias emitidas por los tribunales ordinarios, es decir, no existía el llamado amparo judicial o amparo casación (el actual amparo directo). A partir del famoso "amparo Vega", en el que la SCJN llevó a cabo una interpretación del artículo 14 de la Constitución de 1857, nació un tipo de control constitucional, consistente en vigilar la "exacta" aplicación de la ley, que terminó llamándose control de legalidad. Con el tiempo, todos los juicios del país terminaron federalizándose mediante el amparo casación, lo cual provocó un enorme rezago en la SCJN. Para paliarlo, se crearon los tribunales colegiados, mediante una reforma constitucional (1987-1988), los 
que se encargaron desde entonces de los amparos-casación (actualmente llamados amparos directos).

No obstante, a la Corte se le permitió revisar, en una segunda instancia, algunos amparos directos que tuvieran ciertas características extraordinarias, a saber: aquellos en los que se hubiera reclamado la constitucionalidad de una norma general o en los que se realizara alguna interpretación directa de la Constitución. Es aquí donde nacen las cuestiones "propiamente constitucionales", en contraste de las "cuestiones constitucionales impropias" o de legalidad. Consecuentemente, en México los conceptos legalidad y constitucionalidad se prestan a distintas confusiones. Por legalidad se entiende: a) conformidad entre leyes y actos, y b) un tipo de control constitucional, vía amparo directo, mediante el cual se detectan vicios in iudicando que producen violaciones a la Constitución; mientras que por constitucionalidad, se entiende: c) cuestiones propiamente constitucionales (constitucionalidad de normas generales e interpretación directa de la Constitución), y d) cuestiones de constitucionalidad impropia, que coinciden con las cuestiones de legalidad identificadas con la letra b).

3. Otro aspecto importante a destacar es que la movilidad de la frontera no es inocua, ya que pone en entredicho el principio de justicia formal, dado que, de hecho, no siempre se trata de la misma forma a seres pertenecientes a una misma categoría: los quejosos. Esta situación, si bien no constituye un ilícito típico, sí puede calificar como uno atípico (un fraude a la ley), en el que lo que se viola no es una regla sino un principio: el de igualdad.

4. En cuarto lugar, en el Semanario Judicial de la Federación existen cuatro - y no dos - categorías de casos relacionadas con la procedencia del recurso de revisión en el amparo directo; a saber: 1) cuestiones propiamente constitucionales; 2) cuestiones de mera legalidad; 3) cuestiones de constitucionalidad forzada, y 4) cuestiones de legalidad forzada. Las dos primeras representan las zonas de claridad de uno y otro concepto, mientras que las restantes, la zona de penumbra. La movilidad de la frontera, se insiste, no es algo baladí, ya que muchos asuntos que la Corte no debiera resolver, los termina resolviendo, con lo cual se aleja de la aspiración de consolidarse cono un auténtico tribunal constitucional; por el contrario, cuando deja de resolver asuntos que tenía la obligación de atender, incumple su misión como tribunal protector de derechos o defensor de la Constitución. 
5. En quinto lugar, detecté dos causas que generan la movilidad de la frontera: 1) el comportamiento de los ministros asociado a sus preferencias teóricas, y 2) algunas razones políticas. La primera causa tiene que ver con las preferencias y el grado de conciencia teórica de los ministros que han venido integrando la SCJN. La jurisprudencia de la Corte revela un comportamiento teóricamente heterogéneo, derivado naturalmente de las preferencias de cada uno de sus miembros. Ello no tendría nada de particular - al contrario, nos hablaría de un sano pluralismo - si no se detectaran - en no pocas ocasiones - excesos y errores derivados del uso ideológico de determinadas concepciones, tales como el formalismo y el activismo. La segunda causa es de carácter político. No podemos cerrar los ojos ante la evidente influencia que desde el exterior condiciona, o al menos influye, en las decisiones sobre procedencia o improcedencia de un amparo directo en revisión. Esas decisiones no dependen únicamente del talento académico o del dominio del método jurídico del operador, sino también de los factores reales de poder - especialmente económicos y políticosque inciden en algunas decisiones de la Corte, ante una débil concepción de independencia judicial. Más que entenderla como un auténtico deber o como una virtud judicial, la independencia judicial es entendida como una serie de garantías, beneficios, o incluso "derechos" a favor del juez. Nada más alejado de la realidad, puesto que tales garantías no son sino el marco institucional adecuado para que los jueces ejerzan su independencia. Más que un derecho o un privilegio, la independencia es un deber correlativo al derecho de los ciudadanos a ser juzgados estricta y exclusivamente desde el derecho.

6. Más allá de los anteriores hallazgos, conviene preguntarnos: ¿qué reflexiones se derivan de todo lo anterior? En primer lugar, conviene preguntarnos cómo debería ser la procedencia del recurso de revisión en aras de paliar la desigualdad que actualmente se genera a causa de la discrecionalidad. ¿Debería eliminarse toda posibilidad de que la SCJN resolviera cuestiones de legalidad, como se pretendió inicialmente, mediante la eliminación de la cláusula de la importancia y trascendencia? O, por el contrario ¿debería permitirse que la SCJN decidiera libremente qué tipo de asunto, sin importar si es de legalidad o de constitucionalidad?

Soy consciente de que la solución que llegara a elegirse debería perseguir una mayor estabilidad en el sistema, es decir, un modelo normativo que disminuyera razonablemente el grado de indeterminación para que, por regla general, los casos seleccionados para ser analizados de fondo 
por la SCJN fueran del mismo tipo. La estabilidad de un sistema jurídico depende en gran medida de la seguridad, que por regla general refleja la aplicación del derecho en la resolución de los conflictos sociales. Los casos excepcionales siempre y en todos lados seguirán existiendo, pero hay buenas razones para preocuparse cuando la excepcionalidad prevista por el propio sistema crece de forma irracional.

7. Una segunda reflexión tiene que ver con los cambios legislativos que necesita la legislación sobre el juicio de amparo. Uno de los múltiples ajustes urgentes son reglas claras sobre la procedencia del amparo directo en revisión. Una fórmula que se ha discutido recientemente para paliar ese problema por algunos ministros (Aguilar Morales, Ortiz Mena o el ministro en retiro Cossío Díaz) es el establecimiento de un mecanismo de selección discrecional y no recurrible de asuntos relevantes a cargo de la propia Corte, a manera de certiorari. Quizá no sea descabellado tratar de emular lo que les ha funcionado a las altas cortes de algunos países como Estados Unidos, España, Colombia o Argentina. Con ello, la Corte mexicana resolvería el problema de la oscuridad de los criterios para elegir, y se dedicaría en exclusiva a generar una doctrina constitucional propiamente dicha, lo cual traería beneficios incuestionables, tales como la disminución del formalismo, la consolidación de la supremacía constitucional, el fortalecimiento del sistema de precedentes, el aumento de la coherencia en sus decisiones, el crecimiento de la certeza y la seguridad jurídica y, en general, una mejor defensa de los valores constitucionales.

8. En tercer lugar, es preciso mejorar la capacitación de los operadores judiciales y sus equipos. La capacitación judicial propia del paradigma constitucionalista implica una orientación muy distinta a la de los programas tradicionales de formación jurídica basados casi exclusivamente en la memorización de textos y procedimientos. A mi juicio, conviene sembrar una conciencia teórica en los juristas prácticos que les permita entender mejor cuáles son los fines últimos de la práctica jurídica.

9. Finalmente, resulta indispensable repensar la idea de jurisprudencia, que, como sabemos, en nuestro país está muy lejos de ser un genuino sistema de precedentes. Las reglas jurisprudenciales se multiplican cada día, formando un universo inabarcable, y no siempre coherente, que se suman al ya de por sí extenso conjunto de leyes y tratados. El principal problema de nuestra jurisprudencia es que las reglas son abstractas, es decir, separadas de los hechos que originaron el conflicto, que se aplican por los jueces 
sin haber constatado la analogía entre el caso que originó la regla y el caso que va a resolverse con ella.

\section{BIBLIOHEMEROGRAFÍA}

Aguiló Regla, Josep, “Independencia e imparcialidad de los jueces y argumentación jurídica”, Isonomía. Revista de Teoría y Filosofía del Derecho, México, núm. 6, abril de 1997.

AtIENZA RodríGUEZ, Manuel, "Siete tesis sobre activismo judicial", 2018, disponible en: http://lamiradadepeitho.blogspot.com/2018/10/ siete-tesis-sobre-el-activismo-judicial.html.

ATIENZA RodRÍGUEZ, Manuel, "Ni positivismo jurídico ni neoconstitucionalismo. Una defensa del constitucionalismo postpositivista", Revista Argentina de Teoría Jurídica, Argentina, Universidad Torcuato di Tella, vol. 15, núm. 2, diciembre 2014.

AtienZA Rodríguez, Manuel, Curso de argumentación jurídica, Madrid, Trotta, 2013.

Atienza Rodríguez, Manuel y Ruiz Manero, Juan, Ilícitos atípicos, Madrid, Trotta, 2000.

Código Iberoamericano de Ética Judicial, publicación en línea: http:// www.poderjudicial.es/cgpj/es/CIEJ/Codigo-Iberoamericano-de-EticaJudicial/.

FAVOREAU, Louis, Legalidad y constitucionalidad. La constitucionlización del derecho, traducción de Magdalena Correa Heano, Bogotá, Universidad Externado de Colombia, Instituto de Estudios Constitucionales Carlos Restrepo Piedrahita, 2000.

FIX-FIERRO, Héctor, "El amparo judicial y la «imposible tarea» del Poder Judicial de la Federación. Perspectivas en el centenario de la Constitución de Querétaro", en FERRER MAC-GREGOR, Eduardo y HERRERA GARCÍA, Alfonso (coords.), El juicio de amparo en el centenario de la Constitución mexicana de 1917, t. I, México, UNAM, Instituto de Investigaciones Jurídicas, 1917.

FIX-ZAMUDIO, Héctor, "El amparo mexicano como instrumento protector de los derechos humanos", en Garantías jurisdiccionales para la defensa de los derechos, México, UNAM, 1993. 
GONZÁLEZ OropeZA, Manuel, "El amparo en negocios judiciales. El caso de Manuel Vega", Anuario Mexicano de Historia del Derecho, vol. X, México, 1998.

Mayer-Serra, Carlos Elizondo y Magaloni KerPel, Ana Laura, "El «alegato de oreja» inequidad y mediocridad", Boletín Mexicano de Derecho Comparado, México, 2015.

Oficina de las Naciones Unidas CONTRA la DROGA Y El Delito (UNODC), Comentario relativo a los Principios de Bangalore sobre la conducta judicial, Viena, 2013.

Perelman, Chaïm y OlBretchs-TyteCA, Lucie, Tratado de la argumentación. La nueva retórica, traducción de Julia Sevilla Muñoz, Madrid, Gredos, 1989.

Pozzolo, Susana, "Neoconstitucionalismo y especificidad de la interpretación constitucional", Doxa 21, vol. II, España, Universidad de Alicante, 1998.

Pou GiMÉnEZ, Francisca, "El nuevo amparo mexicano y la protección de los derechos: ¿ni tan nuevo ni tan protector?”, Anuario de Derechos Humanos, Santiago, Centro de Derechos Humanos de la Facultad de Derecho de la Universidad de Chile, 2014.

RABASA, Emilio, El artículo 14 y el juicio constitucional, México, Porrúa, 1993.

Suprema CoRTE de Justicia de la NACión, Informe Anual de Labores, presentado por el ministro presidente, Luis María Aguilar Morales en diciembre de 2016, disponible en: https://www.scjn.gob.mx/sites/default/ files/informe_labores_transparencia/version/2016-12/IN FORME\%20 MINISTRO\%20PRESIDENTE\%202016.pdf.

Suprema Corte de Justicia de la NAción, Acuerdo General número 9/2015, de ocho de junio de dos mil quince, del Pleno de la Suprema Corte de Justicia de la Nación, que establece las bases generales para la procedencia y tramitación de los recursos de revisión en amparo directo, disponible en: http://dof.gob.mx/nota_detalle.php? codigo $=5396550$ \&fech $a=12 / 06 / 2015$.

SERNA DE LA GARZA, José María, "El amparo-casación en el pensamiento de Emilio Rabasa”, en GonZÁlez MARTíN, Nuria (comp.), Estudios jurídicos en homenaje a Marta Morineau, t. I: Derecho romano. Historia del derecho, México, UNAM, Instituto de Investigaciones Jurídicas, 2006. 
SHAPIRO, Scott, Legality, The Belknap Press of Harvard University Press, 2011. Existe una versión castellana: Legalidad, traducida por Diego M. Papayannis y Lorena Ramírez Ludeña, Madrid, Marcial Pons, 2014.

Fecha de recepción: 1 de octubre de 2019.

Fecha de aceptación: 16 de enero de 2020. 